\title{
Assessment of Policies and Harm Reduction Services for Young People Who Use Drugs in Kathmandu Valley of Nepal: Identifying Gaps and Opportunities
}

Ishwor Maharjan ( $\square$ ishwor@youthrise.org )

Youth RISE

\section{Research}

Keywords: Young People who use drugs, Harm Reduction Services, Young people who inject drugs, Nepal

Posted Date: January 3rd, 2022

DOI: https://doi.org/10.21203/rs.3.rs-1099205/v1

License: (9) This work is licensed under a Creative Commons Attribution 4.0 International License.

Read Full License 


\section{Abstract}

Background: Young people under 30 represent the majority of people who use drugs in the Kathmandu Valley, Nepal. Young people who use drugs (YPWUD) may have particular needs and require different service and policy responses when compared to their older peers. This research examines the strengths and limitations of currently available policies and services; their effectiveness in meeting the needs of YPWUD and identifies gaps and opportunities for their improvement.

Methodology: Semi-structured interviews $(n=9)$ with key stakeholders and one focus group $(n=5)$ discussion with YPWUD were conducted. Results were analyzed using the Rhodes Risk Environment framework which considers the 'physical', 'social', 'economic' and 'policy' level factors shaping risk at 'micro', 'meso' and 'macro' levels.

Results: Drug use patterns among YPWUD in the Kathmandu Valley, Nepal are changing. Several trends have been identified including increased use of methamphetamine, diverted pharmaceuticals and 'Southasian-Cocktail' (a mixture of buprenorphine, benzodiazepine and antihistamines); use at the border regions and a move away from drug dealing 'hotspots' to online drug purchasing. YPWUD and service providers report a range of barriers to accessing services including stigma and discrimination; a lack of local services; a lack of knowledge of existing services; age of consent legislation and opening hours which may conflict with commitments such as school and college. YPWUD report a range of human rights violations including involuntary treatment, arbitrary detention, forced labour and public body searches. Service providers and policymakers report precarious international donor funding of services through HIV prevention programs with little to no youth-specific services for YPWUD.

Conclusion: The findings of this study highlight the importance of youth-friendly harm reduction services that are relevant and responsive to the unique needs and experiences of YPWUD. These services should address current trends including the use of new substances (for example, methamphetamine and 'Southasian Cocktail') in diverse environments (including at the border regions and online). The perspectives of YPWUD are vital while developing and implementing harm reduction programs to ensure that the programs are effective, efficient and based on the diverse needs of YPWUD.

\section{Introduction}

Drug use is a complex phenomenon and young people who use drugs (YPWUD) are likely to require specialized approaches in terms of program and policy design and development to meet their healthcare needs(1). Young people are at higher risk of HIV infection compared to other age groups mainly due to unsafe sex and injecting practices(2). Even though data on the age of people who inject drugs (PWID) has not been collected systematically, there are recent reports of increased risk behavior leading to higher HIV incidence in young PWID(3)

Although harm reduction programs are well established in many western countries(4), people who use drugs (PWUD) in most low and middle-income countries have limited and inequitable access to HIV and 
HCV prevention and treatment services(5-7) and lack services focused on and accessible to young people(8). YPWUD face an extra burden in accessing harm reduction services as age restrictions and requirements for parental consent can make accessing NSEP, opioid substitution treatment (OST) and HIV and HCV testing less accessible to young people(9).

Many factors can influence the help-seeking behavior of YPWUD including that the frequency with which young people inject varies, many may not have developed dependence and they may have not yet experienced adverse consequences for their health(8). Many of them may also not identify as a PWUD or see themselves as needing any guidance or treatment(8). Gurung(10), conducted a survey of 350 YPWUD in Nepal and concluded that harm reduction services did not meet their needs with $68 \%$ of those surveyed reporting that all available services were not youth-friendly. This study will build on this work with a particular focus on Kathmandu Valley.

A wide range of factors may influence YPWUDs' experience of harm reduction including physical, social, economic and policy-level factors $(11,12)$. Such issues include those surrounding access to the service; suitability (the degree to which services are 'youth-friendly); the long-term sustainability of programs; internal and external stigma; service provider discrimination; laws and policies which criminalize the behaviors of PWUD; low literacy rates and other individuals/social factors(11).

There exists a paucity of data relating to the YPWUD experience of harm reduction services in Nepal. This study identifies key issues with a view of identifying practices, gaps and opportunities with an aim of developing a set of recommendations on how harm reduction services and existing laws and policies could better respond and adapt to the needs of YPWUD. This research aims to inform service delivery, implementation and policies for YPWUD in the Kathmandu Valley, Nepal and to identify any knowledge gaps in the area. through the following objectives

\section{Method}

Semi-structured interviews and focus group discussions were conducted with key Nepalese drug policy stakeholders. Interview schedules for both the semi-structured interviews and focus group discussions are attached in the appendix (A1). Interviewees were recruited from key Nepalese drug policy stakeholder populations identified by Gurung(13), namely, those at "policy", "harm reduction service" and "community" levels.

Policy level study respondents were identified due to their level of involvement in harm reduction policy and contacted by email. Harm reduction service level respondents were identified by their location (Kathmandu Valley, Nepal) and also contacted per email. Community-level respondents were recruited through the use of service provider 'gatekeepers' which recruited respondents through their respective services.

Inclusion and exclusion criteria were defined based on the focus of this study and to collect the key datas from the experts in their relevant area. The following table (Table 1) defines the criteria to include 
participants for this study.

Table 1

Inclusion and exclusion criteria

\begin{tabular}{|c|c|c|}
\hline Level & Inclusion criteria & Exclusion criteria \\
\hline Policy & $\begin{array}{l}\text { Working on drug policy related issues in } \\
\text { Nepal }\end{array}$ & $\begin{array}{l}\text { Not working on drug policy } \\
\text { issues specifically }\end{array}$ \\
\hline \multirow[t]{3}{*}{$\begin{array}{l}\text { Harm reduction } \\
\text { service delivery }\end{array}$} & $\begin{array}{l}\text { - Involved in operating/implementing harm } \\
\text { reduction services for YPWUD. }\end{array}$ & $\begin{array}{l}\text {-Not focussed on drug specific } \\
\text { harm reduction activities. }\end{array}$ \\
\hline & $\begin{array}{l}\text { - Involved in operating/implementing harm } \\
\text { reduction services in Kathmandu valley. }\end{array}$ & $\begin{array}{l}\text { - Not based in Kathmandu } \\
\text { valley. }\end{array}$ \\
\hline & $\begin{array}{l}\text { At least } 2 \text { years experience working in harm } \\
\text { reduction }\end{array}$ & $\begin{array}{l}\text { 'Less than } 2 \text { years' experience } \\
\text { working in harm reduction }\end{array}$ \\
\hline \multirow[t]{5}{*}{ Community } & - Above 18 years. & $<18$ years. \\
\hline & $\cdot<30$ year. & $\cdot>30$ years old \\
\hline & - Member of YPWUD community. & -Not using drugs. \\
\hline & - Experience of using harm reduction services & $\begin{array}{l}\text { No experience of using harm } \\
\text { reduction services. }\end{array}$ \\
\hline & - Living in Kathmandu Valley & $\begin{array}{l}\text {-Living outside Kathmandu } \\
\text { Valley }\end{array}$ \\
\hline
\end{tabular}

Interviews and the focus group discussion were conducted in Nepali and recorded. Online interviews were conducted by the primary researcher $(n=3)$. In-person interviews $(n=6)$ were conducted by a peer investigator at the respective NGO offices of respondents (Recovering Nepal, Lalitpur; Sathi Samuha, Kathmandu; YKP LEAD Nepal, Lalitpur; Sparsha Nepal, Lalitpur and Aavash Samuha, Lalitpur and Bhaktapur). An in-person focus group discussion $(n=5)$ was conducted by 2 peer investigators at Aavash Samuha, Lalitpur.

Nine semi-structured interviews were conducted with stakeholders at the 'Policy, 'Harm Reduction Service levels'and 'community level. Focus groups were conducted at the 'community level with five YPWUD. In Figure 1, a schematic diagram of the study is presented, showing key stakeholders who took part in the research. 
Table 2

Focus group participant demographic

\begin{tabular}{|llll|}
\hline Participant & Gender & Age & Geographic location \\
\hline Participant 1 & Male & 20 & Lalitpur \\
\hline Participant 2 & Male & 20 & Lalitpur \\
\hline Participant 3 & Male & 23 & Kathmandu \\
\hline Participant 4 & Male & 24 & Kathmandu \\
\hline Participant 5 & Male & 24 & Bhaktapur \\
\hline
\end{tabular}

Transcripts of the interviews and focus group discussions were analyzed according to our conceptual framework which utilized both Rhodes $(11,12)$ and Bronfenbrenner(14),namely, by considering 'physical', 'social, 'economic' and 'policy factors at 'micro', 'meso' and 'macro' levels.

\section{Results}

In this section, results are analysed using the Risk Environment Framework, namely, through the domains of 'physical', 'social, 'economic' and 'policy environments. Sub themes in each domain are discussed under each domain (See: Table 6). 
Table 6

Risk environment for YPWUD in the Kathmandu Valley, Nepal

\begin{tabular}{|c|c|c|c|}
\hline Environment & Micro & Meso & Macro \\
\hline \multirow[t]{3}{*}{ Physical } & $\begin{array}{l}\text { Access and availability of } \\
\text { services issues }\end{array}$ & Availability of drugs & \multirow[t]{3}{*}{ Drug use at border } \\
\hline & Human right violations & $\begin{array}{l}\text { Availability of } \\
\text { services }\end{array}$ & \\
\hline & $\begin{array}{l}\text { Physical issues affecting } \\
\text { YPWUD }\end{array}$ & & \\
\hline \multirow[t]{3}{*}{ Social } & Peer norms & $\begin{array}{l}\text { Stigma and } \\
\text { discrimination }\end{array}$ & \multirow[t]{3}{*}{$\begin{array}{l}\text { Criminalization and human } \\
\text { rights }\end{array}$} \\
\hline & Drug trends & Police harassment & \\
\hline & Knowledge of services & & \\
\hline \multirow[t]{2}{*}{ Economic } & \multirow[t]{2}{*}{ Financial issues } & \multirow[t]{2}{*}{ Corruption } & Donor funding \\
\hline & & & Government funding \\
\hline \multirow[t]{2}{*}{ Policy } & \multirow[t]{2}{*}{ Age restriction } & Policy development & Policy responsibility \\
\hline & & $\begin{array}{l}\text { Need of youth } \\
\text { friendly policies }\end{array}$ & $\begin{array}{l}\text { Policy implementation and } \\
\text { coordination }\end{array}$ \\
\hline
\end{tabular}

\subsection{Physical environment}

\section{Access and availability of services issues}

YPWUD reported that existing services did not meet their needs whilst service providers also reported that existing services were sub-optimal. It was reported that there is not enough adequate service coverage for PWUD in Nepal. Geographic proximity and opening hours are reportedly creating challenges and barriers for YPWUD who are seeking access to services. An office approach (e.g. 9am-5pm), for example, can exclude YPWUD $(15,176-177)$ as '..if a user is studying, then they have to go to school or college at the same time when the service sites are open. What we can do is at least to manage time which is favorable to them' $(18,252-254)$.

Additionally, some YPWUD who live outside the main cities of Kathmandu valley are facing difficulties accessing harm reduction services, because they are not available in the outskirts and they 'have to travel 2-3 hours on a bus' to reach services ( $12,134-136)$. Unlike other health services, harm reduction services are not available outside of the cities ' for example, above Bhaktapur, those parts are impossible to reach, similarly, in Lalitpur, there are many unexpected places where there are many PWUD. That's why if I have to say in terms of accessibility, only $60 \%-70 \%$ is covered and still, there is a gap of $30 \%$ (11, 209-212). As 
a result, harm reduction services are not available to a larger number of YPWUD living in other parts of the country.

Services were also reported to lack several of the 9 key components of harm reduction programs recommended by the World Health Organisation (WHO)(15). Condoms and NSEP were included alongside OST but other key components were not $(15,154-159)$. YPWUD were referred to other services for these components (ibid.).

\section{Human right violations}

Some of the present practices of law enforcement (police) were identified by several respondents as barriers for accessing services. This included fear of harassment and pre-trial detention by police and fear of forced involuntary treatment. These practices discourage YPWUD from accessing services. Involuntary treatment was considered one of the worst-case scenarios. Cases of kidnapping of PWUD by rehabilitation centers were also reported to be increasing (14, 8-11).

\section{Availability of drugs and drug use at border}

The easy availability of illicit drugs on the illicit market was mentioned to be a significant factor in terms of drug use among YPWUD. Some of the most commonly used drugs were reported to be pharmaceutical drugs with opioid-based painkillers, heroin, methamphetamine and an injected mixture called 'South Asian Cocktail (composed of opioid-based painkillers, diazepam and antihistamines) reported to be popular among this group.

Nepal shares an open border with India. Several respondents reported drug use at the border regions. YPWUD often cross the border to buy and use drugs because it is easily accessible in Indian pharmacies at much cheaper prices $(11,68-71)$. A newly emerging trend is the supply of drugs through social media sites. This has led to the gradual disappearance of physical drug 'hot spots' with YPWUD shifting online as a safer and more secure way to access drugs (I1, 76-80).

\section{Physical issues affecting YPWUD}

Abscesses, DVT (deep vein thrombosis), vein collapse, bloodborne diseases, overdoses and even death are commonly occurring negative health outcomes of YPWUD. These problems can start very early with many problems such as 'abscesses, DVT, overdoses, vein collapse' often starting within the first two years of drug use (I1, 18-20; I2, 12-15; I4, 110-111; I3, 11-12; I6, 28-30). However, a lack of abscess management programs and dressing clinics in Kathmandu valley has been reported $(14,54-55 ; 14,110$ 111).

\subsection{Social environment}

\section{Peer norms and drug trends}


Drug use behaviors and patterns of young people can be influenced by various factors. All respondents reported that illicit drug use was increasing, especially among young people. A majority of the population using drugs are reported to be ' 75 to $76 \%$ are the youth population below the age of 30 . Even in our harm reduction services, there are mainly two age groups: 14-19 years old and 20-25 years old who use our services' (11, 6-10).

Local trends were reported to affect the drug-using pattern of YPWUD, for example synthetic drugs like ice or yaba (methamphetamine) were reported to be gaining popularity with these drugs being easily accessed by YPWUD $(11,35-38 ; 13,21 ; 14,13-16)$. Many YPWUD were reported to start injecting '.. when they are 13-14 years old but still, they can't access services'(16, 83-85). YPWUD were also reported to be increasingly moving away from injecting in injecting hotspots and are '..nowadays they are using it in their homes' (18, 59-67; 17, 171-178).

\section{Knowledge of services}

Most of the respondents $(110,92-97 ; 110,114-116 ; 11,280-281 ; 18,13-34 ; 19 ; 102-105)$ highlighted that, YPWUD are not well informed regarding harm reduction services. Many YPWUD were reported to be unaware of even government-run OST services- not knowing 'where and how to get to that service' with most 'informed by the peer to peer. But there is nothing which informs PWUD regarding the available services' (11, 256-259).

\section{Stigma and discrimination}

Several respondents discussed how shame and a fear of damaging their family's reputation/status in society can discourage them as well as their family to talk about and seek help for their problems related to drug use.

'First thing in the context of Nepal, the word drug use is considered as a synonym of stigma ... there is a fear of what dad, sister, or any other members of family will say, a fear the family status in society will degrade, and so on. Due to these stigmas, PWUD feels unsafe to open and come out' (I3, 160-165).

Thus, societal perspectives play a vital role if an individual participates in harm reduction services or not. One of the YPWUD confirmed the difficulty accessing harm reduction services saying that, 'Most of us are afraid that if our relatives or society will find out that we are using, then they will see us in a negative perspective' $(110,100-102)$.

Elements of Nepalese society were reported to be hostile to both YPWUD and harm reduction service providers. Harm reduction services providers are often perceived as 'distributing free drugs and promoting drug use' $(110,85)$ and there can be opposition to opening services 'due to the negative perspective towards harm reduction services' $(12,114-116)$. As a result, YPWUD may often be subject to stigma and discrimination including the use of perjorative slurs $(11,65-66)$. This stigma and discrimination may negatively affect being able to connect with YPWUD populations;' $50-60 \%$ of 100 is easy but at the end 
reaching last remaining $5-10 \%$ which is hidden due to criminalization or stigma and discrimination, will be very difficult'(18, 60-62).

\section{Police harassment}

A key reported barrier for YPWUD accessing services and those supplying them with injecting equipment was regular harassment by the police. Police were reported to interact with YPWUD $(110,62-63)$ and outreach workers $(14,70-72)$ for carrying injecting equipment which sometimes led to interrogation on the stress, detention and arrests (110, 56-60; 13, 43-46).

\section{Criminalization and Human Rights}

Most respondents highlighted that a paradigm shift in public discourse as well at governmental and official authorities level should take place. The approach of criminalization was considered to be ineffective; 'This approach doesn't work in any country and it doesn't reduce drug use or mitigate issues related to drug use' (I3, 51-53).

In the context of prohibition, YPWUD were reported to often go through unnecessary interrogation, threats of imprisonment, body searches and bullying even whilst accessing harm reduction services. YPWUD are reportedly frequently targeted and blamed for crimes, arrested and harassed $(15,210-217)$ and they advocate for revision of the punitive law and policies and provide treatment services:

'The law says drugs can be provided with the prescription of a doctor so based on that OST programs were implemented. The way out can be seen now but still, the criminalization of drug use needs to be removed $(15,104-106)$.

\subsection{Economic environment}

\section{Financial issues}

Poverty may also impact the decision of YPWUD to initiate injecting drug use: 'The accessibility to injecting drugs is high because it is relatively cheaper compared to the price of heroin, that is why these injecting drugs are most common among youths' (11, 32-34). One of the respondents stated that, 'the risk and intake of drugs have increased mainly among people without employment and who are not studying' $(17,15-16)$. Further another respondent adds, 'the condition of a country is poor which leads to instability in the households as well and this leads people to use drugs. Therefore, there should be more focus on rehabilitating PWUD and creating employment opportunities and training them etc. And mainly it should be continued and sustained (I2, 51-53).

\section{Corruption}

Harassment from corrupt police officers was considered a significant barrier to accessing services $(15,95$ 101). In this context, police officers receive monetary compensation as a commission for supplying YPWUD to rehabilitation centres as is illustrated in the following experience; 
'Couple of days ago an incident happened to me. When I was walking, the police stopped me and took me to the station where there were some rehab people waiting for us and as soon as we reached there, those rehab people and police started to ask about my family and their number. After a while, my family came there and those police gave an option to my family that either they should send me to rehab and pay for it or they will send me to jail even though I have done nothing, just because they (police and rehab) knew that I'm a drug user. But my family didn't have money to send me to rehab so they said they can't afford it or pay anything so do what you want. Fortunately, staff from the harm reduction service center came later to bail me out' (110, 121-129).

\section{Funding}

The Nepalese government currently spends less than 5\% of GDP on its health budget, though this spending increased from 2019 to $2020(11,245-249)$. However, there are no specific budgets for harm reduction programs from the government. Although policies and strategies that promote harm reduction have been developed they are rarely followed up with action plans with allocated funding (I5, 220-224). Donors sometimes fill these gaps but they tend to fund and prioritize primary needs, leaving secondary needs like youth or women-specific services unmet (ibid.). This is particularly problematic as 'due to lack of financial support, we are unable to provide many other essential services which we could have provided along with current programs from a donor (Global Fund) through Save the Children'(12, 103103). As a result, many services remain sub-optimal and are not able to conduct a range of activities (I8, 203-208).

Most services are funded by foreign donors and are under constant fear of losing funds and thereby shutting down important harm reduction services. In this context, the cessation of The Global Fund funding is of particular concern $(11,185-189)$.

\subsection{Policy environment}

\section{Youth-friendly policies}

All respondents outlined a need for youth-friendly harm reduction services as '.. it will attract youths and will make it easy for them as well as us to provide services' $(4,80-81)$. Several suggested they should be independent services whilst others stated that due to the lack of funding such services should be integrated into current harm reduction programs. The lack of differentiated care is identified as another obstacle for the respondents of harm reduction services. An UNAIDS representative working in Nepal explains why there is a need for differentiated care for YPWUD;

'In terms of HIV programs, there is a new terminology called 'Differentiated Care', which means providing services as per the needs of different groups. For e.g., if there are 100 PWUD, the same program will not work for all 100. Therefore, these kinds of innovative ideas are not included in our national strategies but 
still, we are informing them (policymakers) about these different approaches and advocating to include these innovative approaches in national strategies but unfortunately, it's not been included yet' $(17,86-92)$.

Rehabilitation centres are reported to apply a blanket one size fits all type of approach to care. 'In rehab centers, they use a blanket approach which means using the same approach for all. Even though there are different users in ... And it is proven that the same approach of treatment doesn't work for all. Therefore overall knowledge on drugs is needed, even for YPWUD' $(13,215-219)$.

Several respondents representing the national and international organizations were also concerned about the age of initiation into drug use and the lack of access to services. A recent Integrated Biological and Behavioural Surveillance (IBBS) study, for example, found that 'many users who are around 15 years old' $(18,261-271)$. In theory, under 18 s can access services under certain circumstances (family consent). In practice, however, YPWUD are frequently referred to rehabilitation services $(15,68-73)$ and may lack family consent to attend services due to the stigma discussed earlier $(110,100-102)$.

The Nepalese government may be considered very progressive, 'one of the best policies in southeast Asia. In terms of strategies there should be a different program for women, different programs for the young key affected population, like that which is very nice strategies and policies. However, the law must be reformed to follow up on these policies and this has not occurred yet' $(15,109-114)$. Concurrently, even the 9 indicated WHO interventions won't suffice as there are '..many different kinds of youths, some living in streets, etc. Therefore, programs should be developed in such a way that covers the other areas of YPWUD like providing support during a food crisis, living crisis, etc. so programs need to be designed to address these issues as well $(15,292-297)$.

A reluctance to provide YPWUD with access to harm reduction services was reported. A prevailing belief is that as YPWUD have just started using drugs they should be 'counseled and forced to rehabilitation rather than providing them with harm reduction services' $(15,26-31)$ and activists are '..always raising this issue by explaining to them how the harm reduction services can save lives and help to overcome the health hazard related to drug use' (ibid).

\section{The HIV focus of policies}

A lack of one-stop service centers where PWUD can enjoy comprehensive harm reduction services was highlighted by several respondents. Most of the existing harm reduction services were reported to focus on HIV prevention rather than the health and human rights of YPWUD.

Many Nepalese government authorities and partners along with foreign donors and institutions are reportedly primarily focused on HIV-related issues (11, 245-249; I3, 77-79; 19, 61-66). Harm reduction may often be delivered as part of HIV prevention programs. One of the harm reduction service providers explains the services at their center; 'We are providing various harm reduction services under HIV prevention programs, like NSEP, OST services where we provide both methadone and buprenorphine medicines.."(11, 102-110). 
The programs are constantly being revised. Currently, there is a policy focus on young people which is an indication that at least the first step towards a youth-friendly service provision can be made. 'The new HIV strategy plan (2021-2026) is focused on youths. This new strategy plan specifically focuses on the young key affected population (YKP) and prioritizes the programs for YKP.'(I5, 20-23).

\section{Policy implementation and coordination}

A contradiction between the approaches used by the Ministry of Home Affairs and the Ministry of Health and Population to tackle drug-related issues has been reported For example, the Ministry of Home Affairs enforces the criminalization of drug use as a preventive measure and prioritizes demand and supply reduction approaches. In contrast, the Ministry of Health and Population describes drug use as a health issue and prioritizes harm reduction approaches:

'Sometimes I feel like we are failing to manage these two different perspectives. We as health workers are just looking at it through a health perspective and they as in control perspective. That's why I think we are having problems' $(18,112-122)$.

The contradiction arises when the two ministries do not coordinate with each other. For example, under the Ministry of Health and Population, needle syringes are distributed freely to PWUD as a harm reduction approach but at the same time, law enforcement which operate under the Ministry of Home Affairs arrest and detain PWUD for possessing the same needle syringes distributed under Ministry of Health and Population authority.

Gaps in coordination between law enforcement authorities and health workers, including service providers and civil society networks were identified. In some areas, like upholding and ensuring the human rights of PWUD , law enforcement authorities had a better role to play while in others health workers were accountable. Polar views on defining and dealing with the same issue of drug use among these key players are reportedly leading to a blame game where consistent coordination effort was found to be critical.

The coordination between law enforcement agencies, harm reduction services providers and the YPWUD was reportedly lacking in overall harm reduction program management. The representative of the National Center for AIDS and STD control portrays the anger in these words; 'Police work is not just to capture PWUD but also to give them opportunities to rehabilitate. So, if these could be linked, then the service coverage will also get better. Similarly, and mainly to run OST service centres, it's mandatory to get a permission form Ministry of Home Affairs. Therefore, in terms of site scale up there is a bit of reservation from their side that's why it's halted. So, there is a need to advocate these issues as well (17, 124-128).

\section{Limitations}


This research was conducted using purposive sampling techniques with a limited number of respondents in the Kathmandu Valley, Nepal. YPWUD living in rural areas were underrepresented and intersectional issues were not considered in depth. Representatives of the Ministry of Health and Population and Ministry of Home Affairs did not agree to participate in this research. This is a significant limitation of the study as these departments are central for the relevant policy making. YPWUD under 18 could not be interviewed due to legal restrictions around the age of consent. Quantitative data are not considered, for example, number of services or population size estimates. Also, this research does not directly consider in-depth issues related to the ongoing COVID-19 pandemic which has dramatically altered service deliveries and policies.

\section{Discussion}

YPWUD are initiating drug use at a younger age and increasingly use cannabis, methamphetamine, pharmaceutical drugs and 'cocktails' drug preparations like 'South Asia Cocktail'. This follows similar trends reported by Nepal Drug Users' Survey (16), which reported that drug use amongst all PWUD (76.2\% under 30 years) was increasing $5.06 \%$ annually. YPWUD appear to be moving increasingly online to purchase their drugs(16).

An increased trend of early initiation into injecting drug use has also been reported (16, 83-85). High rates of injection of preparations such as 'South Asia Cocktail' (composed of morphine, diazepam and histamines) expose YPWUD to increased risk of HIV and other comorbidities when compared to other preparations(17). YPWUD reportedly quickly develop abscesses, deep vein thrombosis and other forms of injecting-related harms as has been reported in other literature $(18,19)$. However, there is a lack of easily accessible services for abscesses, DVT, thrombosis and other vein-related diseases to meet their needs.

As has been reported elsewhere(10), this study found that YPWUD lack knowledge of harm reduction services including where and how to access them. Peer education was identified as a viable strategy for increasing knowledge and awareness of services. Where services exist, YPWUD can be restricted by geographic limitations and lack access to transport. Additionally, age of consent laws can become a key barrier for accessing services as has been identified in other jurisdictions(20). YPWUD may lack parental consent and are often fearful of disclosing service needs to their parents about substance use due to potential stigma and discrimination.

This stigma and discrimination can lead to a lack of acceptance of harm reduction services and a preference for zero tolerance and drug free approaches. In this context, society, service providers and policymakers may prefer involuntary treatment to harm reduction services for YPWUD. This is particularly worrying as this common practice(21) has been associated with human rights abuses that have been reported in $\mathrm{Nepal}(22)$.

A lack of coordination and dialogue amongst many stakeholders including governmental departments, other policymakers, service providers and community groups in the area of harm reduction has been reported. In some cases, policy goals were found to be diametrically opposed, for example, the opposing 
goals of the Ministry of Health and Population and the Ministry of Home Affairs. Such debates are commonplace in the literature(23) but are rarely as pronounced in group level policies. A particularly stark example of this dissonance is the arrest of YPWUD and harm reduction providers for carrying injecting equipment distributed for free by the Ministry of Health and Population.

Several respondents highlighted the importance of government funds to ensure the sustainability and effectiveness of harm reduction services. Most of the relevant Nepalese policy objectives and priorities relate to HIV prevention(24) to align with donor funding. In this context, policymakers have committed to harm reduction services and services for YPWUD(25) but in practice these are mostly provided through funding from international donors. Additionally, although $76.2 \%$ of people reporting drug use were under 30 years of age(16) there have been no commitments for youth-specific harm reduction services. This may become particularly problematic when international funders stop funding projects with The Global Fund ending its funding programs in 2024 being highlighted as a particular area of concern $(11,185-189)$ $\therefore$...Even current funding is not enough to make the program comprehensive and to address the specific needs of different groups like females or youth. It will be impossible once the GF pulls out the funding in 2024' (ibid). In other countries, national governments have not stepped in to fund projects previously funded by The Global Fund after they left(26).

Due to the diverse nature of the population, needs-based youth-friendly services are warranted(20). However, this study found that youth-friendly services were largely non-existent and a 'one size fits all' approach was often taken with little consideration to specific needs such as those of women and girls and YPWUD. Often services were delivered as part of HIV prevention services and mostly did not include all components of the WHO $(15,154-159)$.

This study provides qualitative data around harm reduction service provision for YPWUD in the Kathmandu Valley, Nepal. Study findings provide rich data around current trends, issues, needs and environmental factors leading to risk. These will inform current approaches, service delivery and policy implementation for YPWUDs by contributing to the evidence-base for guidelines and manuals for the effective implementation of youth friendly harm reduction services in Nepal.

Future research could consider larger non-purposive samples for greater generalizability of findings. Research with stakeholders in rural areas and other regions of Nepal should be explored to identify regional variations and differences between rural-urban harm reduction service environments. Many intersectional issues (for example, poverty, homelessness, gender-related issues) arose in this research and should be considered in more depth in future research. The ongoing COVID-19 pandemic has also brought about significant changes in the risk environments for YPWUD which should also be considered in more detail in the future.

\section{Conclusion}

This study sought to identify the major challenges for the development and implementation of effective and efficient harm reduction services for YPWUD; understand YPWUD experiences in using harm 
reduction services; identify key barriers for accessing services; identify the most prevalent drug-related issues for YPWUD and identify potential areas of policy and service delivery innovation. Existing national drug laws and policies in Nepal do not correspond to the realities of current drug markets and trends. They also do not correspond to public health-based and human rights based approaches. It is suggested for the stakeholders to revise existing laws and policies in Nepal and take further actions:

\section{Policy areas:}

- Introduce alternatives to coercive sanctions and ensure that suggested alternatives are not violating human rights of YPWUD.

- Reform national laws to decriminalize use and possession of drugs for personal use.

- Ensure the provision of drug treatment, rehabilitation, prevention and other health care and social services in the community and in prison settings.

- Abolish sentencing for drug dependence.

\section{Economic areas:}

- National investment for youth-friendly services.

- Invest in peer-led initiatives and include them into the harm reduction and other health services teams.

- Harm reduction services for YPWUD should be developed and funded.

- The Clinical Guidelines for OST should should be implemented in practice.

- Age of consent should be lowered.

\section{Physical areas:}

- Health services for YPWUD should be accessible.

- Working hours of harm reduction services should be adapted to the needs of YPWUD

- Services offered within harm reduction services should be expanded and should include all the essential harm reduction services- One Stop service.

- Pilot interventions of overdose prevention and other harm reduction services(like DVT and abscess management) should be considered

\section{Social Areas:}

- Protection of human rights should be prioritised and abuses should be investigated and prevented.

- Promote initiatives to reduce stigma and discrimination towards YPWUD

- Increase collaboration - coordinating and collaborating mechanisms need to be developed and practiced between law enforcement authorities and health workers, including service providers and civil society networks. 


\section{Declarations}

\section{Ethics approval and consent to participate:}

This study received ethical approval from Management Center Innsbruck (MCl) university.

\section{Consent for publication:}

All study participants provide informed consent for publication.

\section{Availability of data and materials:}

Anonymized interview transcripts of the interviews are available upon request.

\section{Competing interests:}

The author reports no conflict of interest for this study.

\section{Funding:}

This study was self-funded.

\section{Authors' contributions:}

The author devised, conducted, analyzed, and reported on the study results.

\section{Acknowledgements:}

The author would like to acknowledge Eliza Kurzevic and Florian Scheibein who provided feedback on the initial draft of this paper.

\section{References}

1. The Global Fund. Harm Reduction for People Who Use Drugs: A Technical Brief [Internet]. The Global Fund. 2020 [cited 2021 Nov 16]. Available from: https://www.theglobalfund.org/media/1279/core_harmreduction_infonote_en.pdf

2. Ganapathi L, McFall AM, Srikrishnan AK, Kumar MS, Anand S, Lucas GM, et al. Young people who inject drugs in India have high HIV incidence and behavioural risk: a cross-sectional study. Journal of the International AIDS Society. 2019;22(5):e25287.

3. United Nations Office on Drugs and Crime. World Drug Report 2020. Drug Use and Health Consequences. [Internet]. United Nations publication, Sales No. E.20.XI.6. 2020 [cited 2021 Nov 16]. Available from: https://wdr.unodc.org/wdr2020/field/WDR20_Booklet_2.pdf

4. International Harm Reduction Association. What is Harm Reduction? A position statement from the International Harm Reduction Association [Internet]. International Harm Reduction Association 
Briefing . 2010 [cited 2021 Nov 16]. Available from:

https://www.hri.global/files/2010/08/10/Briefing_What_is_HR_English.pdf

5. Larney S, Peacock A, Leung J, Colledge S, Hickman M, Vickerman P, et al. Global, regional, and country-level coverage of interventions to prevent and manage HIV and hepatitis $\mathrm{C}$ among people who inject drugs: a systematic review. The Lancet Global Health. 2017 Dec;5(12):e1208-20.

6. Degenhardt L, Peacock A, Colledge S, Leung J, Grebely J, Vickerman P, et al. Global prevalence of injecting drug use and sociodemographic characteristics and prevalence of HIV, HBV, and HCV in people who inject drugs: a multistage systematic review. The Lancet Global Health. 2017 Dec;5(12):e1192-207.

7. Government of Nepal M of HNC for A and SC. Country Progress Report NEPAL: To Contribute to Global AIDS Monitoring Report 2017 [Internet]. Joint United Nations Programme on HIV/AIDS (UNAIDS). 2018 [cited 2021 Nov 16]. Available from:

https://www.unaids.org/sites/default/files/country/documents/NPL_2018_countryreport.pdf

8. World Heath Organization. HIV and young people who inject drugs: a technical brief. HIV and Young People Who Inject Drugs: A Technical Brief [Internet]. World Heath Organization . 2015 [cited 2021 Nov 16]. Available from: https://www.who.int/publications/i/item/WHO-HIV-2015.10-eng

9. United Nations Office on Drugs and Crime, International Network of People Who Use Drugs, Joint United Nations Programme on HIV/AIDS, United Nations Development Programme, United Nations Population Fund, World Health Organization, et al. Implementing Comprehensive HIV and HCP Programmes with People who use drugs [Internet]. United Nations Office on Drugs and Crime. 2017 [cited 2021 Nov 16]. Available from:

https://www.unaids.org/sites/default/files/media_asset/2017_HIV-HCV-programmes-people-whoinject-drugs_en.pdf

10. Bikash Gurung. Exploratory Survey Research on Young People Who Use Drugs in Nepal. [Internet]. Youth RISE. 2013 [cited 2021 Nov 16]. Available from: http://fileserver.idpc.net/library/Youth-RiseNepal-drug-related-services.pdf

11. Rhodes T. Risk environments and drug harms: A social science for harm reduction approach. International Journal of Drug Policy. 2009 May;20(3):193-201.

12. Rhodes T. The 'risk environment': a framework for understanding and reducing drug-related harm. International Journal of Drug Policy. 2002 Jun;13(2):85-94.

13. Bikash Gurung. "In the Name of Creating Drug Free Society": a Qualitative Investigation on Implications of Drug Law Enforcement on Harm Reduction Programs and People Who Inject Drugs in Kathmandu Valley, Nepal. Journal of Health Research [Internet]. 2016 [cited 2021 Nov 16];30. Available from: https://he01.tci-thaijo.org/index.php/jhealthres/article/view/80735

14. Bronfenbrenner $U$. Toward an experimental ecology of human development. American Psychologist. 1977;32(7):513-31.

15. World Health Organization, United Nations Office on Drugs and Crime, Joint United Nations Programme on HIV/AIDS (UNAIDS). WHO, UNODC, UNAIDS technical guide for countries to set 
targets for universal access to HIV prevention, treatment and care for injecting drug users. [Internet]. Worl Health Organization. 2009 [cited 2021 Nov 16]. Available from: https://www.unaids.org/sites/default/files/sub_landing/idu_target_setting_guide_en.pdf

16. Government of Nepal Ministry of Home Affairs Narcotic Drug Control Section. Nepal Drug Users Survey, 2076 [Internet]. Nepal; 2019 [cited 2021 Nov 16]. Available from: http://www.drugportal.gov.np/assets/uploads/publications/5f060729b42711594145700.pdf

17. Ojha SP, Sigdel S, Meyer-Thompson H-G, Oechsler H, Verthein U. 'South Asian cocktail' - the concurrent use of opioids, benzodiazepines and antihistamines among injecting drug users in Nepal and associations with HIV risk behaviour. Harm Reduction Journal. 2014 Dec 23;11(1):17.

18. Cornford CS, Mason JM, Inns F. Deep vein thromboses in users of opioid drugs: incidence, prevalence, and risk factors. British Journal of General Practice. 2011 Dec 1;61(593):e781-6.

19. Colledge S, Larney S, Bruno R, Gibbs D, Degenhardt L, Yuen WS, et al. Profile and correlates of injecting-related injuries and diseases among people who inject drugs in Australia. Drug and Alcohol Dependence. 2020 Nov;216:108267.

20. Rafaela Rigoni, Global Network of Young People Living with HIV, Youth LEAD, YouthRISE. Harm reduction services for young people who inject drugs [Internet]. 2021 Jun [cited 2021 Nov 16]. Available from: https://youthrise.org/resources/harm-reduction-services-for-young-people-who-injectdrugs/

21. Lunze K, Lermet O, Andreeva V, Hariga F. Compulsory treatment of drug use in Southeast Asian countries. International Journal of Drug Policy. 2018 Sep;59:10-5.

22. Open Society Institute PHP, International Harm Reduction Development Program (IHRD). Human Rights Abuses in the Name of Drug Treatment: Reports From the Field [Internet]. 2009 Mar [cited 2021 Nov 16]. Available from: https://www.opensocietyfoundations.org/publications/human-rightsabuses-name-drug-treatment-reports-field

23. Csete J, Kamarulzaman A, Kazatchkine M, Altice F, Balicki M, Buxton J, et al. Public health and international drug policy. The Lancet. 2016 Apr;387(10026):1427-80.

24. Government of Nepal M of H. HIV epidemic update of Nepal, Fact Sheet 2020 [Internet]. 2020 [cited 2021 Nov 16]. Available from: http://www.ncasc.gov.np/WAD2020/Factsheet-2020-S.pdf

25. Nepal Law Commission. Drug Control Strategy, 2010 [Internet]. Government of Nepal, Law Commission. 2010 [cited 2021 Nov 16]. Available from: https://www.lawcommission.gov.np/en/wpcontent/uploads/2018/09/drugs-control-strategy-2010-1626.pdf

26. The Global Fund. Sustainability, Transition \& Co-Financing [Internet]. The Global Fund. 2021 [cited 2021 Nov 16]. Available from: https://www.theglobalfund.org/en/sustainability-transition-and-cofinancing/

\section{Figures}




\section{Qualitative Study Design}

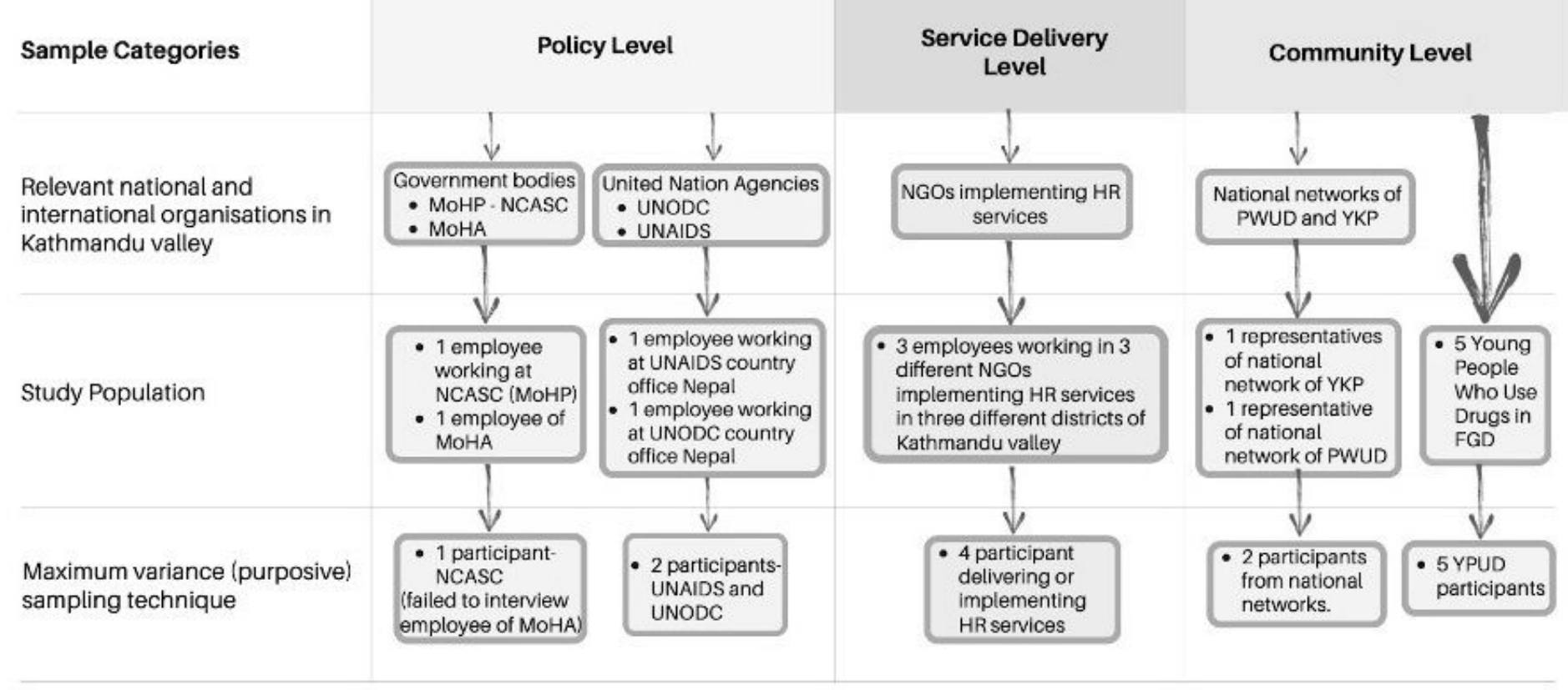

\section{Figure 1}

Schematic Diagram of the Study

\section{Supplementary Files}

This is a list of supplementary files associated with this preprint. Click to download.

- InterviewSchedule.docx 